\title{
A Synthetic Circuit for Mercury Bioremediation Using Self-Assembling Functional Amyloids
}

\section{Citation}

Tay, Pei Kun R., Peter Q. Nguyen, and Neel S. Joshi. 2017. “A Synthetic Circuit for Mercury Bioremediation Using Self-Assembling Functional Amyloids." ACS Synthetic Biology 6 (10) (August 2): 1841-1850. doi:10.1021/acssynbio.7b00137.

\section{Published Version}

10.1021/acssynbio.7b00137

\section{Permanent link}

http://nrs.harvard.edu/urn-3:HUL.InstRepos:34360744

\section{Terms of Use}

This article was downloaded from Harvard University's DASH repository, and is made available under the terms and conditions applicable to Open Access Policy Articles, as set forth at http:// nrs.harvard.edu/urn-3:HUL.InstRepos:dash.current.terms-of-use\#OAP

\section{Share Your Story}

The Harvard community has made this article openly available.

Please share how this access benefits you. Submit a story.

\section{Accessibility}




\title{
A Synthetic Circuit for Mercury Bioremediation Using Self-Assembling Functional
}

\author{
Amyloids \\ Pei Kun R. Tay ${ }^{1,2, \neq}$, Peter Q. Nguyen ${ }^{1,2, \neq}$, and Neel S. Joshi ${ }^{1,2, *}$ \\ School of Engineering and Applied Sciences ${ }^{1}$, \\ Wyss Institute for Biologically Inspired Engineering ${ }^{2}$, \\ Harvard University, Cambridge, MA 02138, USA.
}

$\ddagger$ Authors contributed equally to this work.

*Corresponding author. 


\begin{abstract}
Synthetic biology approaches to bioremediation are a key sustainable strategy to leverage the self-replicating and programmable aspects of biology for environmental stewardship. The increasing spread of anthropogenic mercury pollution into our habitats and food chains is a pressing concern. Here, we explore the use of programmed bacterial biofilms to aid in the sequestration of mercury. We demonstrate that by integrating a mercury-responsive promoter and an operon encoding a mercury-absorbing self-assembling extracellular protein nanofiber, we can engineer bacteria that can detect and sequester toxic $\mathrm{Hg}^{2+}$ ions from the environment. This work paves the way for the development of on-demand biofilm living materials that can operate autonomously as heavy-metal absorbents.
\end{abstract}

\title{
Keywords
}

biofilm engineering, curli, mercury sequestration, biosorption, protein engineering, amyloid 
Mercury is widely circulated throughout the environment as a by-product of industrial processes such as mining, materials processing, coal combustion for power, and as components of chemicals and electronics. These anthropogenic sources of environmental mercury result in the unnatural dissemination and accumulation of mercury compounds in land, freshwater, and marine habitats. ${ }^{l}$ Mercury is a particularly insidious pollutant, as its accumulation in ecological niches increases up through the food chain, a process known as biomagnification. ${ }^{2}$ Humans are typically exposed to toxic mercury compounds through the ingestion of contaminated food sources such as fish or shellfish, leading to damage to tissues of the brain, kidney, and lung. ${ }^{3}$ In utero exposure results in severe developmental abnormalities, resulting in EPA-FDA advisories against eating fish during pregnancy. ${ }^{4}$ Recent studies have found that mercury contamination in the environment is much more prevalent than previously thought, ${ }^{5}$ hence the need for innovative

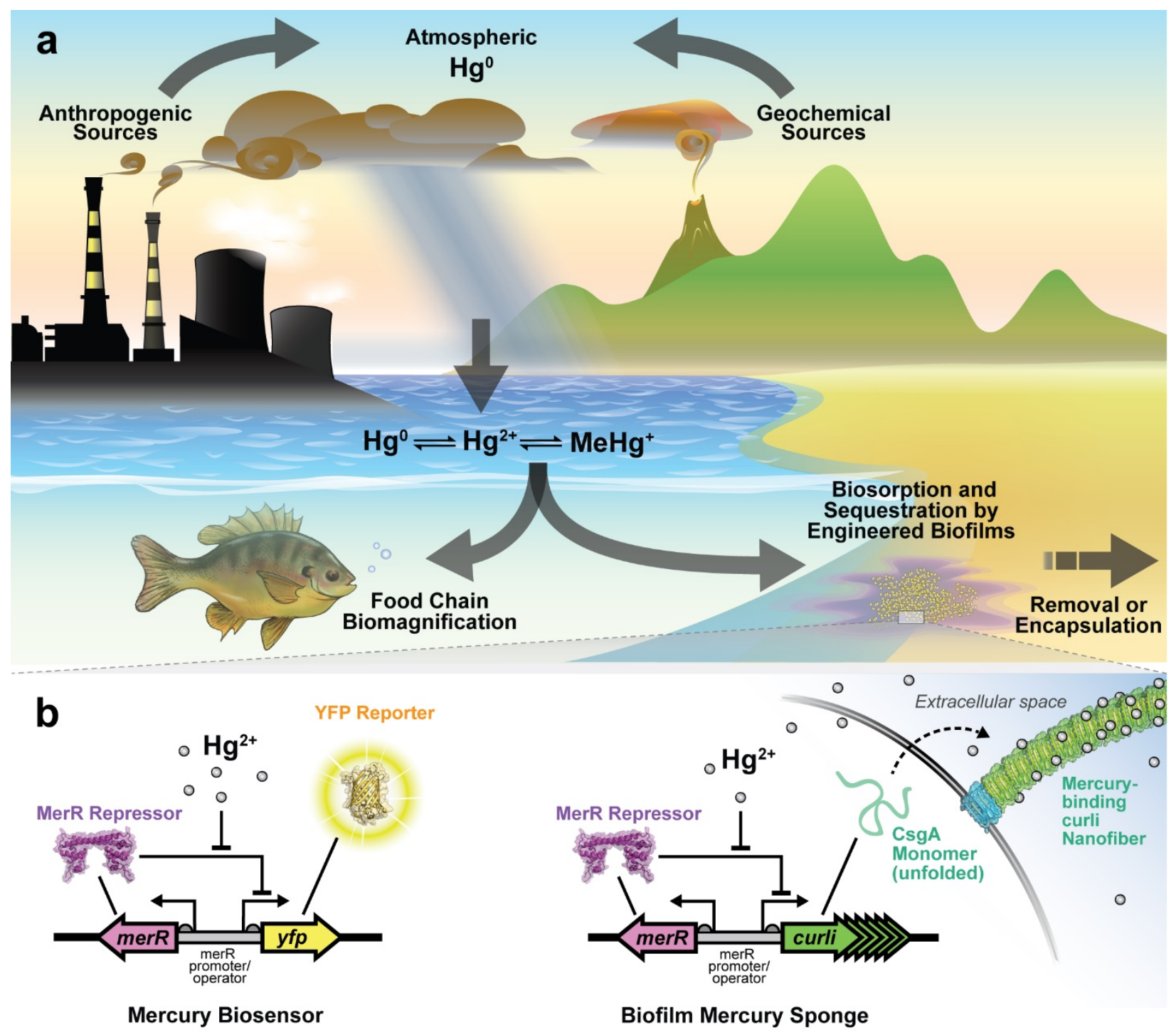

Figure 1. Engineering a synthetic mercury bioremediation circuit. (a) Man-made and natural geochemical processes result in mercury accumulation in the environment and food chains, where it is biomagnified. Engineered synthetic biofilms acting as a mercury sink could be deployed to bind and sequester environmental mercury for bioremediation. (b) Schematic of the MerRregulated $\mathrm{Hg}^{2+}$-binding curli biofilm circuit. The reporter gene in the MerR-based mercury biosensing circuit is replaced with a curli operon encoding the synthesis and export of self-assembling functional amyloids that are able to bind mercury ions. 
approaches to remediating contaminated sites. Of particular interest are scalable, low-cost, and sustainable biological approaches for the detection and sequestration of mercury ions.

Bioengineered mercury sensor circuits employ naturally occurring mercury-responsive transcriptional regulators, such as the MerR regulator. ${ }^{6}$ MerR regulates the expression of the mer operon - a widespread and ancient bacterial operon family found in plasmids and transposonswhich encodes enzymes for mercury detoxification. ${ }^{7}$ Upon binding to $\mathrm{Hg}^{2+}$, the MerR repressor undergoes a conformational change resulting in de-repression of the mer operon. By replacing the mer operon genes with a reporter such as luciferase ${ }^{8}$ or GFP, ${ }^{9}$, mercury-inducible biosensors have been developed that allow for bacterial reporting of environmental mercury. Besides mercury reporters, a number of attempts have been made to use bacteria to bind and sequester mercury. For example, intracellular accumulation of mercury has been engineered into bacteria by the overexpression of heavy metal-binding metallothioneins, with the goal of remediating mercury contaminated water. ${ }^{10}$ However, it was found that the addition of a $\mathrm{Hg}^{2+}$ transport system, encoded by the merT and merP genes, were essential for mercury sequestration. An alternative strategy uses cell-surface displayed mercury-binding proteins, such as a metallothioneins, ${ }^{11}$ phytochelatins, ${ }^{12}$ or the MerR metal binding domain, ${ }^{13}$ to create engineered cellular biosorbents. These examples of engineered bacterial circuits for sensing and absorption of mercury demonstrate the exciting potential of green biological strategies for mercury remediation of contaminated environments. However, the sequestration strategies described above employed externally added chemical inducers (e.g., IPTG) rather than having the cell react dynamically to environmental mercury. Furthermore, these strategies use the cell biomass itself as the mercury sink, which requires continuous energetic investment in biomass synthesis, and would end up poisoning the cell. One promising approach is the use of the extracellular material (ECM) of bacterial biofilms to act as a biosorbent for the extraction of environmental mercury. The high surface area of the ECM could potentially provide much larger absorption capacities than cell surface-based strategies and prevent mercury-induced toxicity to the cell, allowing sustained production of the mercury-binding material. A number of studies have investigated naturally occurring biofilms for their heavy metal absorption characteristics, ${ }^{14,}{ }^{15}$ but to our knowledge, there has not been a rationally designed dynamic gene circuit for the production of a mercury-absorbing bacterial ECM. A robust and autonomously operating biofilm that is able to sequester mercury could act as a sink to remove anthropogenic and geological sources of mercury contamination, for field deployment to reduce the mercury burden in ecological food chains and remediate heavily polluted sites (Figure 1a). Our strategy builds upon efforts from others that use renewable biomaterials, often purified and assembled into a filter matrix in vitro, as materials for heavy metal adsorption. These materials include animal ${ }^{16}$ and plant-derived ${ }^{17}$ biomaterials such as keratin or cellulose fibers as binding agents for the sequestration of various heavy metal contaminants. Of particular interest is the recent exploration of synthetic composites containing self-assembling amyloid fibers as a powerful technology for the removal of heavy metal pollutants. ${ }^{18}$ Amyloids have been known to interact specifically with heavy metals ${ }^{19-21}$ and these complexes can be redox active. ${ }^{18,22,23}$ Such properties have led to a number of amyloid-

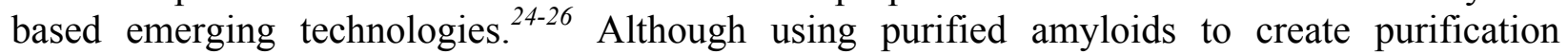
membranes has the advantages of precise control over the final composition of the material and its properties, it still requires purification and engineered assembly steps which may add to cost and complexity of the system. Here, we explore the potential of integrating such amyloid materials technology with synthetic biological principles to create an engineered living 
material $^{27,28}$ capable of fabricating a functional sequestration material in situ only when the pollutant is detected.

Escherichia coli and Salmonella spp. biofilms contain functional amyloids called curli, which are self-assembling extracellular protein nanofibers. ${ }^{29} \mathrm{We}$ and others have recently re-engineered curli fibers for the functional display of peptides and proteins to create dynamic engineered living materials. ${ }^{30-33}$ Curli and similar functional amyloids have evolved as a key biofilm component enabling substrate adhesion, ${ }^{34}$ structural reinforcement of the biofilm, ${ }^{35}$ and host cell invasion. ${ }^{36}$ A recent study by Hidalgo and colleagues suggested that curli might also serve a protective function, specifically by shielding bacteria in biofilms from extracellular mercury through adsorption of the heavy metal. ${ }^{37}$

Based on these findings, we designed and engineered a synthetic circuit that is able to detect mercury in the environment (via MerR) and direct the synthesis of curli nanofibers to sequester mercury ions in an extracellular matrix. The circuit utilizes the divergently regulated MerR promoter $\left(\mathrm{P}_{\text {merR }}\right)$ derived from a Shigella flexneri plasmid, engineered such that MerR is constitutively expressed and represses transcription of either a reporter (YFP) or the curli operon. When present, mercury ions bind to MerR to trigger an allosteric change and allow transcription and expression of the desired output (Figure 1b).

To demonstrate that our circuit responds to mercury, the pET30a- $\mathrm{P}_{\text {merR-curli plasmid was }}$ transformed into a previously engineered E. coli strain, PQN4, in which the entire curli operon has been deleted. ${ }^{38}$ The parental E. coli strain is the MC4100 strain, which advantageously does not produce any other extracellular materials, such as polysaccharides, other fimbrae, or flagella, that may complicate analysis. The MC4100 strain has thus been used extensively in mechanistic and genetic studies of the curli operon. ${ }^{39-41}$ In the wild-type MC4100 background, as in most other wild $E$. coli strains, induction of the genomically-encoded curli operon occurs only under conditions of low osmolarity and/or starvation. ${ }^{42,}{ }^{43}$ By placing this operon instead under the control of a mercury-inducible promoter, we have decoupled curli production from these narrow conditions and have now coupled them instead to the presence of environmental mercury, creating an engineered living material that fabricates a heavy-metal sequestering nanomaterial in response to the detection of that specific pollutant.

The pET30a-P merR YFP and a pET30a control vector were used as controls. Colonies of overnight cultures were spotted onto minimal media agar containing the amyloid-specific dye Congo Red, with or without ionic mercury $\left(\mathrm{Hg}^{2+}\right)$, and left to grow at $30^{\circ} \mathrm{C}$ overnight. Minimal media was chosen to reduce the effect of media components on metal binding. As shown in Figure $2 \mathrm{a}$, curli production was tightly regulated by $\mathrm{P}_{\mathrm{merR}}$ and high expression required the presence of $\mathrm{Hg}^{2+}$. The $\mathrm{P}_{\text {merR }}$-YFP biosensor transformants exhibited mercury-induced fluorescence, indicating proper functioning of the MerR-regulated promoter (Figure S1). There was a graded response, with more curli produced at higher $\mathrm{Hg}^{2+}$ concentrations. This concentration-dependent expression was further demonstrated by culturing cells in suspension overnight with exposure to a range of $\mathrm{Hg}^{2+}$ concentrations. The curli content of the cultures was measured using a Congo Red quantification assay and normalized to the $\mathrm{OD}_{600}$ of the cultures. We confirmed that the presence of mercury did not affect Congo Red binding to curli (Figure S2). In our MerR-regulated curli circuit, induction in liquid media occurred at $600 \mathrm{ppb}$ and above. Induction of curli plateaus at $1000 \mathrm{ppb}$ and was sustained at the maximum concentration 
a

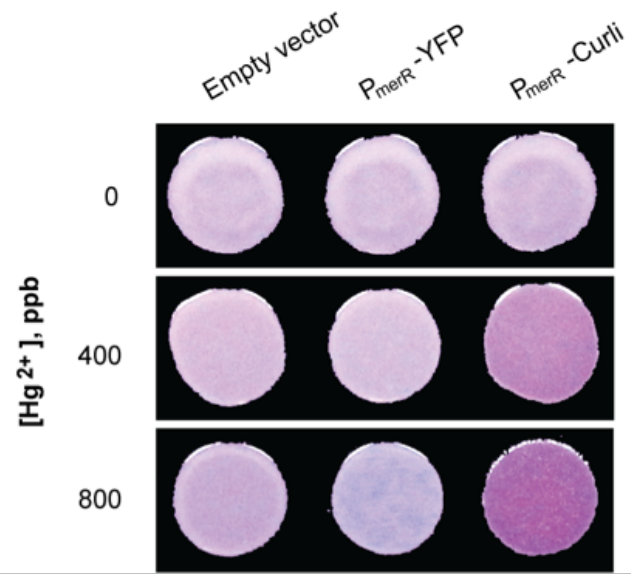

C

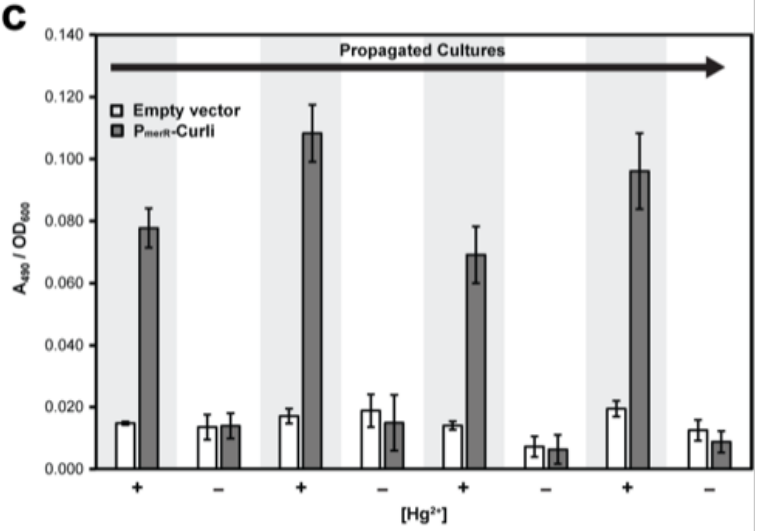

b
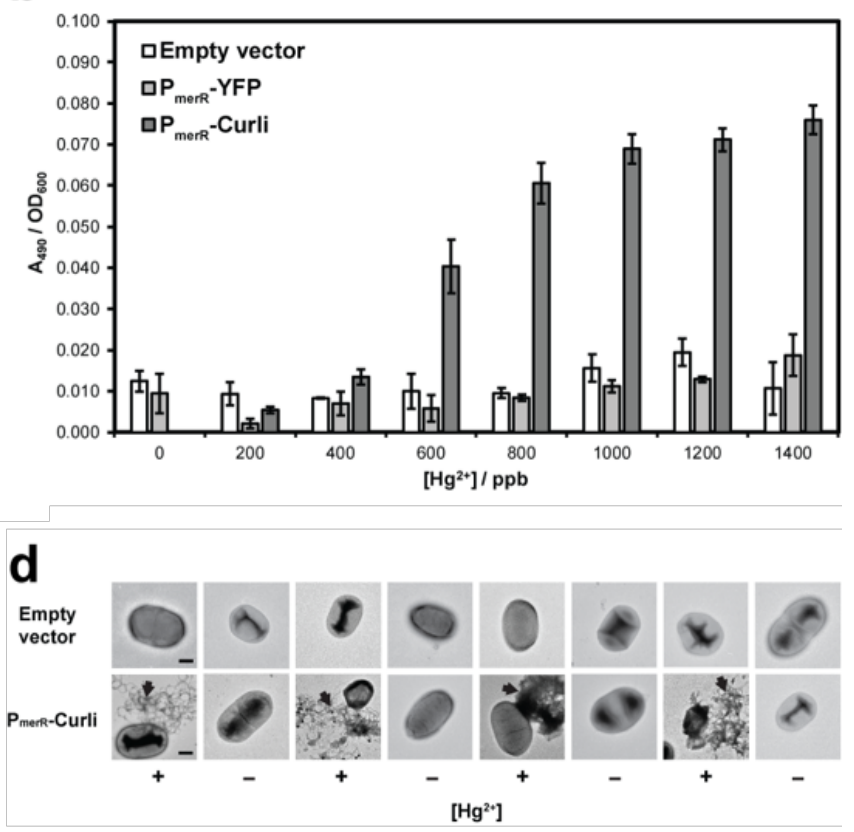

Figure 2. Curli nanofiber production is regulated by environmental mercury $\left(\mathbf{H g}^{2+}\right)$ concentration. (a) The MerR circuit activates the output genes in the presence of $\mathrm{Hg}^{2+}$, as seen with $\mathrm{P}_{\text {merR }}$-curli cells spotted on plates containing the amyloidspecific dye Congo Red. (b) Cells grown in suspension were exposed to a range of $\mathrm{Hg}^{2+}$ concentrations overnight. Quantitation of curli production showed a distinct concentration dependence. (c) Curli production in individually propagated cultures exposed to alternating conditions of $1000 \mathrm{ppb}$ of mercury and no mercury, demonstrating dynamic control of nanofiber production only in the presence of environmental mercury. For each transformation type, individual clones were propagated in quadruplicate. (d) Representative transmission electron micrographs of cells from (c), showing the presence of curli (arrows) only for the $\mathrm{P}_{\text {merR }}$-curli cells exposed to mercury. Scale bars, $500 \mathrm{~nm}$.

tested, $1400 \mathrm{ppb}$ (Figure 2b), but significant amounts beyond background was not detected in the absence of $\mathrm{Hg}^{2+}$ as measured by our CR-binding assay. To examine potential toxic effects of high mercury concentrations on the viability of the cell, we measured the density of the cultures after 24 hours growth for each of the concentrations. At mercury concentrations above $1000 \mathrm{ppb}$,

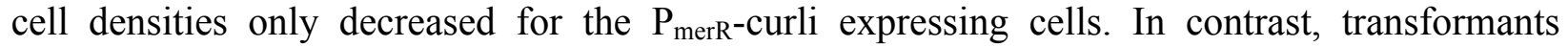
harboring the $\mathrm{P}_{\text {merR }}$-YFP or negative control plasmid (Figure $\mathrm{S} 3 \mathrm{a}$ ) showed no reduced cell density up to $1400 \mathrm{ppb}$. Previous reports have established an $\mathrm{HgCl}_{2} \mathrm{MIC}$ of $2 \mathrm{ppm}$ for E. coli. ${ }^{44}$ The results demonstrate that at these higher mercury concentrations, any negative impact on growth for the $\mathrm{P}_{\text {merR }}$-curli cells is likely due to the metabolic burden of induced protein overproduction rather than mercury toxicity effects on the cell. We also observe similar negative impacts on cell health when the curli operon under control of the strong $\mathrm{P}_{\mathrm{T} 7 / \mathrm{lacO}}$ promoter is highly overexpressed by IPTG induction (Figure S3b). These findings lend support to the utility of our sensing feedback-regulated circuit, in which a metabolically costly nanofiber matrix is fabricated by the cell for sequestering mercury only when mercury is detected in the environment. 

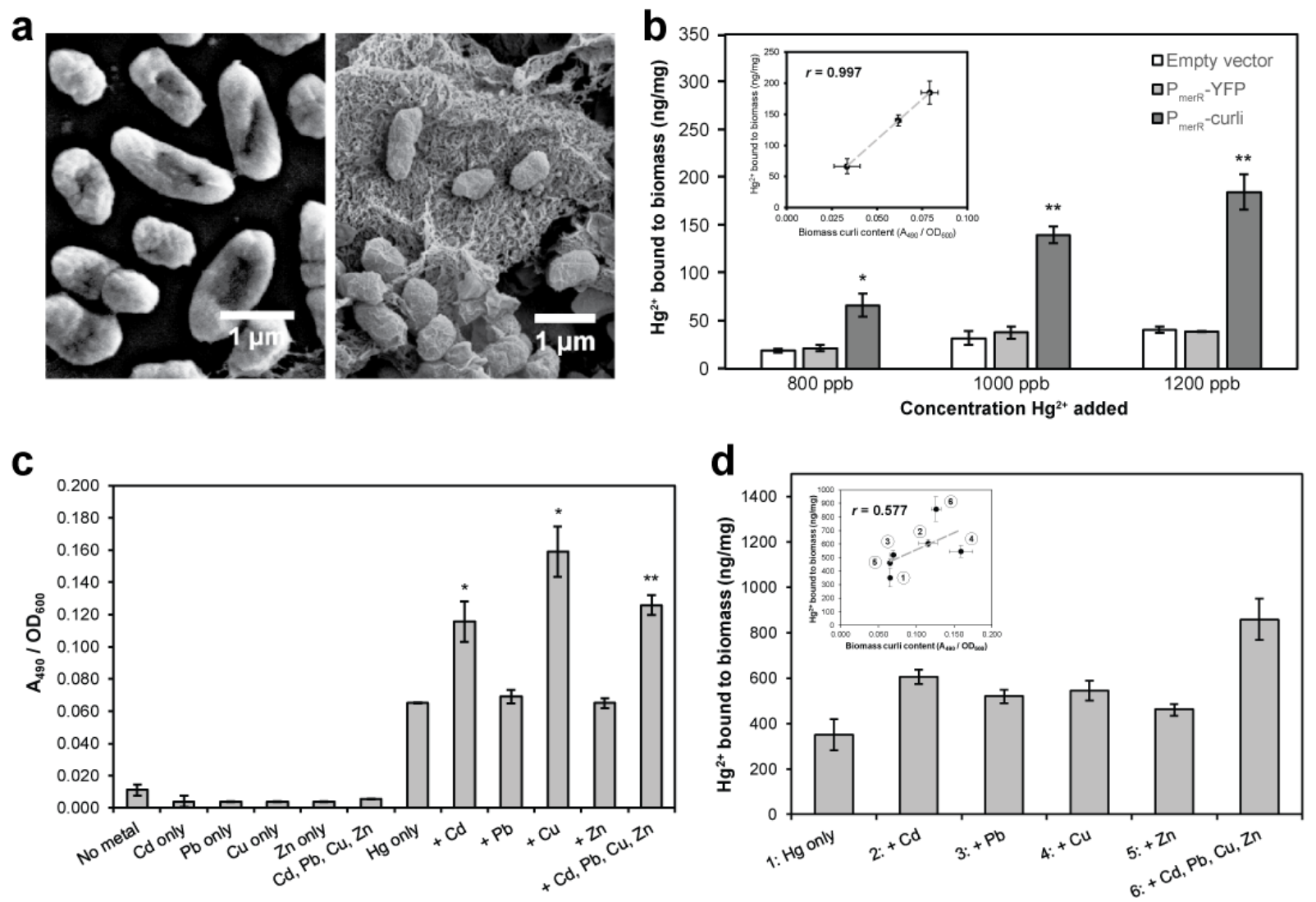

Figure 3. Mercury-induced curli nanofibers sequester mercury from the environment. (a) Scanning electron micrographs

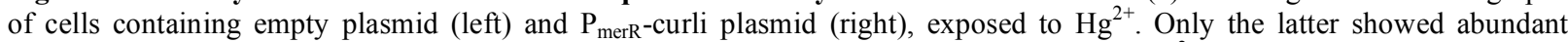
production of extracellular curli nanofibers. (b) Cultures expressing curli showed higher $\mathrm{Hg}^{2+}$ sequestration after overnight exposure compared to non-curliated cultures, as measured by ICP-MS quantitation of bound mercury. The amount of $\mathrm{Hg}^{2+}$ bound correlated positively with the curli content of the culture (inset, $r=$ calculated Pearson correlation coefficient). (c) The MerR circuit is selective for $\mathrm{Hg}^{2+}$, although some divalent metals $\left(\mathrm{Cd}^{2+}, \mathrm{Cu}^{2+}\right)$ could act synergistically with $\mathrm{Hg}^{2+}$ to further enhance curli production. All metals were added at $5 \mu \mathrm{M}$. (d) $\mathrm{Hg}^{2+}$ sequestration by curli fibers was not compromised in the presence of a metal mixture as determined by ICP-MS. Inset shows the Pearson coefficient between the amount of $\mathrm{Hg}^{2+}$ bound and the curli content. * represents $p<0.05$; ** represents $p<0.01$.

As a proxy for solid media such as contaminated soil, mercury-laden agar was used to perform induction experiments on macrocolonies (Figure S4). On solid media, the curli induction response as detected by a quantitative congo red assay appears to be more sensitive to mercury concentrations, occurring at $200 \mathrm{pbb}$ and above. This lower induction threshold in comparison to liquid media is likely due to altered gene expression between the different modes of growth that may influence $\mathrm{P}_{\text {mer }}$ mercury induction and/or the increased likelihood for curli polymerization on solid media due to retarded diffusion. These results demonstrate that such a circuit for generating a mercury-absorbing extracellular matrix can be applied to different forms of contaminated media.

We visually confirmed the presence of dense nanofibers by scanning electron microscopy (Figure 3a). Our circuit was active at mercury concentrations defined for mercury-contaminated sites, ${ }^{45}$ thus making it potentially useful for environmental $\mathrm{Hg}^{2+}$ remediation. Further, the dynamic response of the circuit, as shown for single clonal populations propagated through 
multiple generations, persisted through repeated changes in environmental mercury concentration (Figure 2c).

We next investigated the extent of mercury sequestration by curli-producing cultures. Cultures exposed overnight to $\mathrm{Hg}^{2+}$ were pelleted, dried and analyzed for their mercury content by inductively coupled plasma mass spectrometry (ICP-MS). Curli-expressing bacteria bound 4.5x more mercury on a dry weight basis than cells containing the empty vector when exposed to

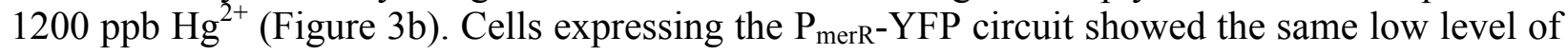
mercury binding as cells with the empty vector (Figure $3 \mathrm{~b}$ ), demonstrating that activation of the circuit alone was not responsible for enhanced mercury sequestration, and the latter was a consequence of curli production. Furthermore, IPTG-induced curli fibers generated by a $\mathrm{P}_{\mathrm{T} 7 / \mathrm{laco}}$ promoter instead of $\mathrm{P}_{\mathrm{merR}}$ also bound to mercury at equivalent levels (Figure $\mathrm{S} 5 \mathrm{a}, \mathrm{b}$ ), indicating that mercury adsorption is due only to the curli fibers and that these nanofibers are functionally identical regardless of the promoter system. TEM analysis also indicates the same ultrastructure for curli fibers produced regardless of the regulating promoter (Figure S5c). The dependence of mercury binding on curli synthesis was more apparent when we looked at

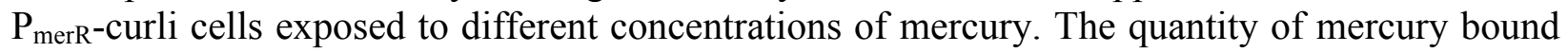
in the biomass correlated significantly to the curli content of the cultures (Figure $3 b$ inset), thus bacteria exposed to higher levels of mercury also sequestered more mercury via the production of more extracellular curli fibers, creating a self-governing mercury-binding system. Curliated cultures were able to retain mercury for over ten days, even after several washes (Figure S6). The mechanism of mercury binding to curli is unclear; there are no cysteine residues in CsgA, though the presence of multiple glutamic and aspartic acid residues along the backbone of assembled fibers suggests an electrostatic interaction. CsgA could also have an inherent ability to reduce $\mathrm{Hg}^{2+}$, as has been demonstrated for the amyloidogenic $\mathrm{A} \beta$ peptide and its reduction of $\mathrm{Cu}^{2+} .46$

Because mercury-contaminated sites could also contain other metal pollutants, ${ }^{47}$ we exposed

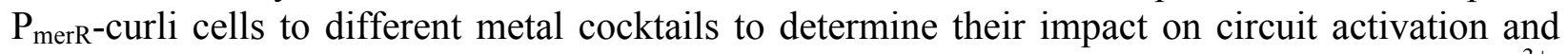
mercury binding to curli. MerR is known to be cross-selective for several other metals $\left(\mathrm{Au}^{3+}\right.$, $\mathrm{Zn}^{2+}, \mathrm{Ag}^{+}, \mathrm{Cd}^{2+}$ ), though higher concentrations of those metals (2-3 orders of magnitude relative to mercury) are required for transcriptional activation. ${ }^{48}$ We tested four divalent metals $\left(\mathrm{Cd}^{2+}\right.$, $\mathrm{Pb}^{2+}, \mathrm{Cu}^{2+}, \mathrm{Zn}^{2+}$ ), none of which induced curli production when used individually or as a mixture at concentrations equivalent to $1000 \mathrm{ppb} \mathrm{Hg}^{2+}$ (Figure $3 \mathrm{c}$ ). Interestingly however, $\mathrm{Cd}^{2+}$ and $\mathrm{Cu}^{2+}$ gave a further increase in curli production when used in equimolar combination with $\mathrm{Hg}^{2+}$, even though $\mathrm{Cu}^{2+}$ is not known to interact with MerR. ${ }^{48,49}$ This hitherto undescribed hetero-bimetallic activation of MerR expands the range of environments in which our circuit could be useful (for instance, in mercury-contaminated sites near copper mines) and its mechanism warrants further investigation. Importantly, the amount of mercury bound by curli-expressing cultures as measured by ICP-MS was not compromised in mixed-metal environments and was actually substantially higher in all cases, although it no longer scaled with curli content, possibly due to interference from the other metals (Figure 3d). One possibility is that the metals could be forming multi-metallic complexes on the curli fibers, which would facilitate $\mathrm{Hg}^{2+}$ deposition and explain improved mercury binding from metal cocktails.

Flocculation of cellular biomass driven by mercury-induced biofilms would particularly aid in the sequestration of mercury by generating a precipitated mass that would consolidate and extract the heavy metal when the contaminant media is liquid, such as leachate or mine tailings 
a
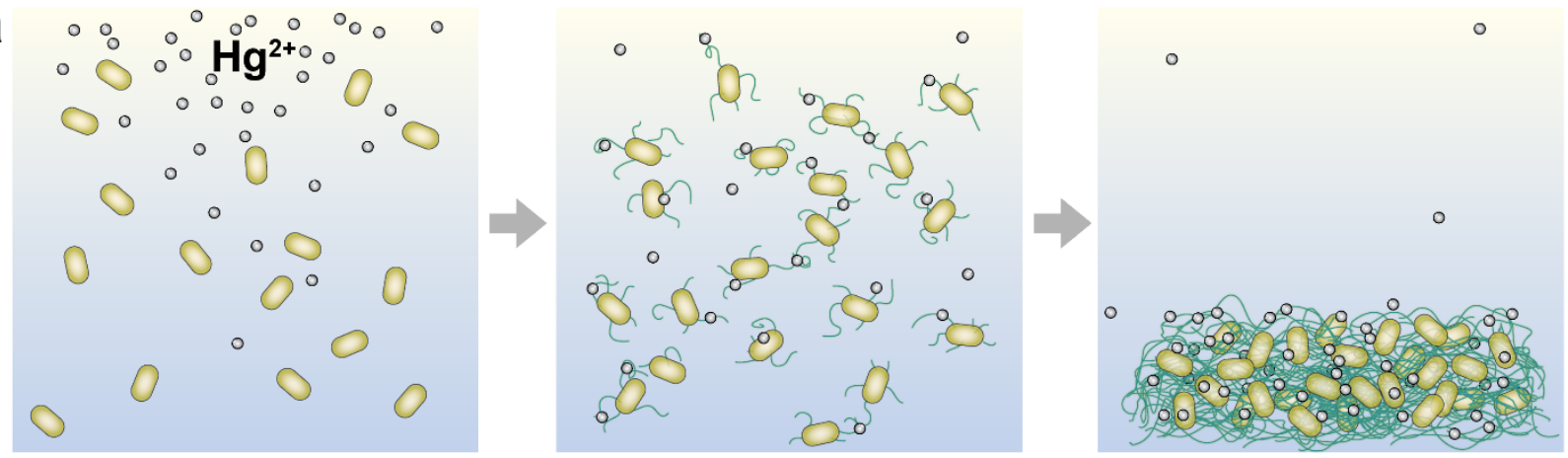

b

C
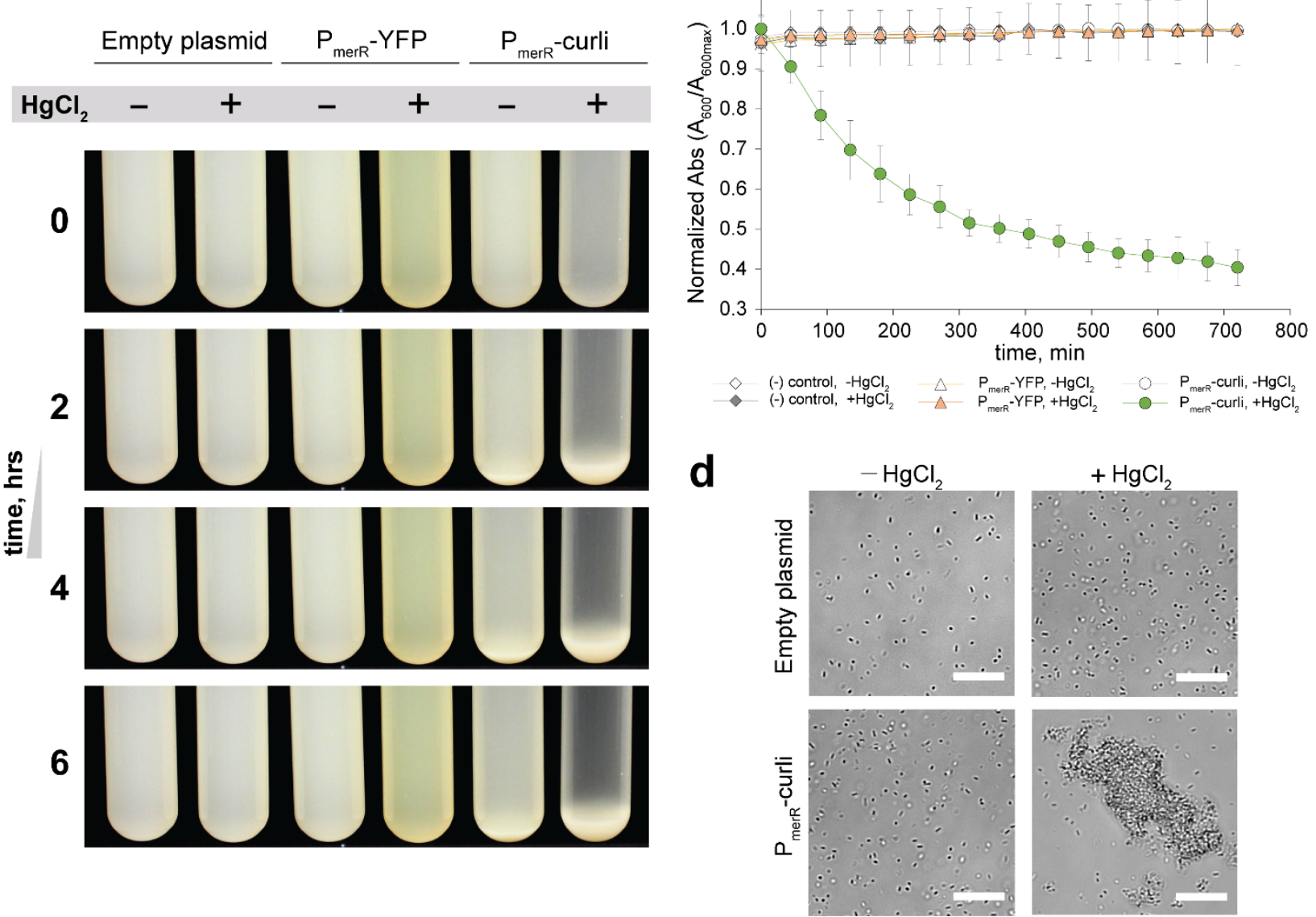

Figure 4. Mercury-induced biofilm flocculation removes mercury-bound biomass from suspension. (a) Schematic showing induction of curli production leading to mercury binding and flocculation of the cells and curli, resulting in sedimentation of the biomass and bulk removal of mercury from the suspension. (b) Images of transformants with no mercury or exposed to $800 \mathrm{ppb}$ of mercury that have been allowed to flocculate and settle over 6 hours. (c) Quantitative sedimentation of the cultures by absorbance measurements. Shown as $n=3$, S.D. (d) Representative microscopy images of cell cultures showing floc formation for $\mathrm{P}_{\text {merR }}$-curli transformants either exposed to no mercury or $800 \mathrm{ppb}$ of mercury. Scale bars, 15 microns.

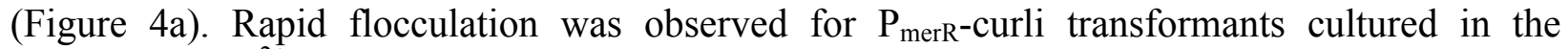
presence of $\mathrm{Hg}^{2+}$, whereas this was not observed for $\mathrm{P}_{\text {merR }}$-YFP or empty vector transformants (Figure 4b-c). Microscopy examination of the cultures showed the presence of large cellular

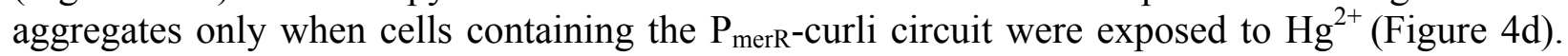


Further studies are warranted to establish any potential influence of mercury cations on curli aggregation, as heavy metals have been found to participate in the aggregation of other amyloids. $^{50}$

Current heavy metal bioremediation strategies face several limitations: where natural biofilms are used, large quantities of biomass are often necessary to compensate for unpredictable and non-specific metal sorption, and even with bacteria genetically engineered to improve their metal binding capacity, the need for costly chemical inducers to sustain the expression of metal binding groups has limited large-scale deployment of these organisms. These engineered systems could theoretically be designed for constitutive or bistable (toggle) expression, but this would result in metabolically wasteful protein production when no heavy metal is present, and compromise the viability of the bacteria in field applications. Such metabolic burden manifests as impaired cellular growth which we observe when the curli operon is overexpressed. These barriers to scalability and robustness have led to synthetic biology efforts exploring the design and engineering of self-regulating dynamic circuits capable of efficient feed-back controlled gene expression. $^{51-53}$ For metabolically costly products such as a large-scale extracellular protein matrix, one of the most efficient regulatory strategies is a feedback-controlled graded response. A number of studies have shown that implementation of in-cell dynamic feedback systems increases the robustness and predictability of engineered synthetic biology circuits and leads to productivity increases. ${ }^{54,55}$ By combining a metal sensing promoter and a metal binding effector protein nanofiber in a single genetic circuit, we have created bacteria that dynamically generate mercury-binding curli amyloid fibers in the presence of environmental mercury. The circuit described herein is responsive to mercury in a sensitive range (above $400 \mathrm{ppb}$ ) that is below that of the trigger threshold for contaminated sites (which ranges from $1-10$ ppm mercury, depending on country) and the mercury MIC (2 ppm) of E. coli, ${ }^{44}$ yet above the experimentally established tolerable limit $(0.13 \mathrm{ppm})$ for soil health in terms of plants and micro-organisms. ${ }^{56}$ This adds a level of precise autonomous selectivity to bioremediation efforts, where metal removal efficiently occurs in situ only in response to a detected contaminant. Our circuit was also selective for mercury even in mixed metal environments which commonly occurs for contaminated sites of previous mining or metal processing facilities, ${ }^{57,58}$ and the curli fibers produced induced flocculation of the cells, further facilitating mercury sequestration and biomass retrieval. The bound mercury was not easily washed off the biomass, thus acting as a strong biogenerated sink for mercury. Curli nanofibers are highly stable, being resistant to proteases, ${ }^{59}$ harsh chemicals, ${ }^{30}$ and detergents and high temperatures. ${ }^{60}$ This makes them ideal for sequestering mercury in a matrix that will not easily break down. Furthermore, the curli fibers form dense nanofibrous networks with an extremely high surface area that would be ideal as an engineered 'sponge' for adsorbing mercury. Although the mechanism of mercury binding and the specific adsorption capacity per mass of curli have yet to be determined, we anticipate future biophysical studies to elucidate these intriguing questions. Additional engineering of the CsgA protein to incorporate metal binding groups could further improve the efficiency of metal removal, although attempts to engineer a small set of mercury-binding motifs into our BIND curli display system resulted in poor secretion and mercury binding inferior to wild-type curli (data not shown).

Here we have presented a synthetic biology circuit in which a mercury-absorbing extracellular self-assembling nanomaterial is fabricated under the control of a mercury-sensing regulatory system. Our initial characterization of this circuit was performed in E. coli, as the 
genetics $^{61}$ and biophysics ${ }^{62}$ of the curli functional amyloid system in E. coli is the most well characterized to date. However, one potential drawback is the relatively low mercury toxicity threshold of E. coli, at $2 \mathrm{ppm}$. Given that the curli functional amyloid is phylogenetically widespread, ${ }^{63}$ exploration of other bacterial chassis that may confer specific phenotypic advantages could greatly expand the operational range, induction sensitivity, and robustness of this circuit for practical deployment. In particular, the circuit could potentially be introduced into a microbe that is uniquely adapted for widespread colonization of the target environment, for instance, soil bacteria such as Bacillus spp. or Shewanella spp., or one that is highly tolerant to mercury $^{14}$, allowing for improved organismal fitness in contaminated environments. One key area for future optimization of our circuit would be improving the induction response of the merR promoter to further increase the sensitivity or alter the response dynamics of induction. This could be undertaken by introducing a transporter for mercuric ions to increase the intracellular mercury levels ${ }^{10}$ or engineering of the MerR regulatory protein. ${ }^{64,65}$ Further engineering to induce toxin precipitation or mineralization within the biofilm ${ }^{66,67}$ would facilitate toxin removal upon disposal of the biofilm or sequester the mercury to prevent it from mobilizing through the biosphere. Given further engineering efforts such as that described above, a mercury-sensing and absorbing engineered living material could be practically implemented in a variety of ways.

One implementation is known as ex situ bioremediation (ESB), which employs fixed- or moving-bed bioreactors and have been implemented in the field for heavy metal decontamination of various media. ${ }^{68,}{ }^{69}$ However, ESB requires excavation of the contaminated media for feedstock as well as downstream separation of the contaminants from the soil or water, which often increases costs. In contrast, in situ bioremediation (ISB) efforts have been investigated as cost-effective green solutions for environmental remediation, and numerous pilot studies have been performed in which bacteria have been injected (in a process known as 'bioaugmentation') into contaminated soil ${ }^{70-72}$ or even deep into the bedrock. ${ }^{73,74}$ While most ISB efforts attempt to utilize unengineered bacterial isolates that can be surprisingly competitive with the indigenous microbial population ${ }^{75}$, there is immense potential for the development of remediation-focused synthetic organisms that can be readily programmable for specific growth conditions or contaminants. ${ }^{76}$ Such genetically-modified bacterium specifically engineered for enhanced bioremediation have already undergone field testing at contaminated sites. ${ }^{77,78}$

We can envision sentinel bacteria populations capable of responding to a variety of environmental toxins by the in situ production of biofilm sponges to sequester toxins at their source, thus preventing significant leaching into surrounding soil or water bodies. Such solidification/stabilization $(\mathrm{S} / \mathrm{S})$ strategies focus on binding or sequestering the toxins at their source in a stabilized mass, trapping the toxins in an insoluble format and reducing mobilization throughout the ecosphere, preventing leaching into highly mobile media (e.g., groundwater) that would facilitate poisoning of food chains. S/S approaches are the most frequently used strategy to treat soil, sludge, and liquid that is contaminated with mercury. ${ }^{69}$ A synthetic biology approach for the implementation of a genetically engineered living material for bioremediation that is able to sequester mercury in a highly stable amyloid matrix at contaminated sites for different forms of media could be considered to be a hybrid approach of ISB and S/S strategies. As contaminated sites are often highly heterogeneous with spatially localized hot spots, the engineered biofilms would selectively populate the regions around the hot spots that are below 
their toxicity threshold, biosynthesizing mercury-adsorbing curli nanofibers in situ. As the biofabricated highly stable nanofibers sequester the local mercury, the cells would be able to colonize further and produce more mercury-sequestering curli. Given the diversity of metalresponsive promoters, ${ }^{79}$ the range of biofilm-specific functional amyloid proteins available for genetic manipulation, ${ }^{80}$ and the recent advances towards displaying functional heterologous peptide and proteins domains on these amyloid scaffolds, this strategy of environmentallytriggered production of engineered biosorptive extracellular matrices could be adapted for the remediation of other toxic metals and environmental pollutants.

\section{METHODS}

Cloning. The $\mathrm{P}_{\text {merR }}$ :YFP mercury reporter plasmid was constructed by Gibson assembly of synthesized DNA fragments (Thermo Fisher Scientific). The merR gene and promoter region was taken from the mer operon of Shigella flexneri 2b plasmid R100. The $\operatorname{csg} B A C$ and $\operatorname{csg} D E F$ divergent curli operons derived from $E$. coli LSR10 were subcloned into a pET30a vector to obtain a single synthetic $\operatorname{csg} B A C E F G$ operon as previously described. ${ }^{38}$ To create the $\mathrm{P}_{\text {merR }}$ :curli operon, the $\operatorname{csg} B A C E F G$ operon was subcloned in place of $y f p$ gene. The negative control plasmid was obtained by completely excising the T7-LacO promoter region from pET30a using Gibson cloning. All plasmids were transformed into PQN4 cells, an engineered E. coli MC4100 strain in which the curli operon was removed by lambda Red recombineering and the T7 RNA polymerase gene integrated into the genome using a DE3 lysogenization kit (Merck Millipore). All cells were plated on LB agar or grown in bacterial medium supplemented with $50 \mu \mathrm{g} / \mathrm{mL}$ kanamycin.

Cell culture and metal exposure. Metals were diluted from 1000 ppm stocks in $2 \% \mathrm{HNO}_{3}$ (High Purity Standards) to the desired final concentrations. Overnight cultures were expanded to $\mathrm{OD}_{600} \sim 0.7$ at $37^{\circ} \mathrm{C}$ in LB. All subsequent experiments involving mercury exposure were performed in supplemented minimal media (GCMM) comprising: $6.78 \mathrm{~g} / \mathrm{L} \mathrm{Na} \mathrm{HPO}_{4}, 3 \mathrm{~g} / \mathrm{L}$ $\mathrm{KH}_{2} \mathrm{PO}_{4}, 0.5 \mathrm{~g} / \mathrm{L} \mathrm{NaCl}, 1 \mathrm{~g} / \mathrm{L} \mathrm{NH}_{4} \mathrm{Cl}, 2 \mathrm{mM} \mathrm{MgSO}_{4}, 0.1 \mathrm{mM} \mathrm{CaCl}_{2}, 0.4 \% \mathrm{w} / \mathrm{v}$ glucose, and 1\% (w/v) casamino acids. Congo Red plates were prepared with GCMM and agarose (Lonza) supplemented with $25 \mu \mathrm{g} / \mathrm{mL}$ Congo Red, $10 \mu \mathrm{g} / \mathrm{mL}$ Coomassie Brilliant Blue and the appropriate concentration of $\mathrm{Hg}^{2+}$. Agarose was used to reduce non-specific binding of mercury to normal bacteriological agar. For protein expression on plates, expanded cultures were pelleted and resuspended in GCMM, and $5 \mu \mathrm{l}$ spotted on Congo Red plates, which were incubated at $30^{\circ} \mathrm{C}$ overnight. For protein expression in suspension, metal was added to GCMM-resuspended cultures to the appropriate final concentration and cultured for at least $18 \mathrm{hrs}$ in $1 \mathrm{~mL}$ deep-well plates $\left(30^{\circ} \mathrm{C}, 900 \mathrm{rpm}\right)$. Three replicate cultures were used for each condition tested. Statistical analysis was performed using the Student's t-test with a 95\% confidence interval. For experiments involving cycling of cells between different mercury concentrations, four single clonal colonies were expanded in $\mathrm{LB}$ to an $\mathrm{OD}_{600} \sim 0.7$. The cultures were pelleted and resuspended in GCMM with or without $1 \mathrm{ppm} \mathrm{Hg}^{2+}$, and allowed to grow for at least $18 \mathrm{hr}$. Samples were collected for TEM imaging, $\mathrm{OD}_{600}$ measurement and quantification of curli expression using the Congo Red assay as described below. The cultures were then normalized to $\mathrm{OD}_{600}=1$, diluted $250 \mathrm{x}$ into fresh LB, and the cycling repeated four times.

Quantitation of protein expression. $100 \mu \mathrm{L}$ of metal-exposed cultures were passed through a 96-well filter plate (MultiScreen Isopore, Millipore). Wells were washed once with PBS and 
shaken with $100 \mu \mathrm{L}$ of $15 \mu \mathrm{g} / \mathrm{mL}$ Congo Red solution for $5 \mathrm{~min}$. The suspension was filtered and the absorbance at $490 \mathrm{~nm}$ of the unbound Congo Red in the filtrate was read on a BioTek H1 plate reader, and used to determine the amount of Congo Red bound to the cultures. Wells were subsequently shaken with $100 \mu \mathrm{L}$ deionized water, and YFP fluorescence was determined on the plate reader (Ex: $485 \mathrm{~nm} / \mathrm{Em}: 550 \mathrm{~nm}$ ).

Transmission electron microscopy. Cell culture samples $(5 \mu \mathrm{L})$ were applied to plasmacleaned formvar/carbon film nickel TEM grids for 1 minute, then washed with $5 \mu \mathrm{L}$ of ultrapure water for 1 minute, and subsequently negative-stained with fresh $2 \%$ uranyl formate for 15 seconds. The samples were allowed to dry for 10 minutes, and then imaged on a JEM-1400 Transmission Electron Microscope at $80 \mathrm{kV}$ accelerating voltage.

Scanning electron microscopy. Nuclepore filter membrane discs containing immobilized metalexposed cultures were fixed overnight in $2 \%$ glutaraldehyde $/ 2 \%$ para-formaldehyde at $4{ }^{\circ} \mathrm{C}$. The discs were immersed in a series of dehydrating ethanol solutions $(25 \%, 50 \%, 75 \%, 100 \%$ $\mathrm{v} / \mathrm{v}$ ethanol), then dried on a Tousimis Autosamdri-931 $\mathrm{CO}_{2}$ critical point dryer. SEM images were obtained on a Zeiss Ultra Plus FE-SEM.

Quantitation of metal binding. 350-450 $\mu \mathrm{L}$ of metal-exposed cultures were pelleted, frozen and lyophilized and the dry weights measured. Pellets were taken up in $250 \mu \mathrm{L}$ concentrated $\mathrm{HNO}_{3}$ $\left(69 \% \mathrm{v} / \mathrm{v}\right.$, trace-metal grade, Fisher), then briefly heated to $95^{\circ} \mathrm{C}$ and sonicated for complete resuspension. The mixture was left to digest at $25^{\circ} \mathrm{C}$ for $1 \mathrm{hr}$ with shaking. Acid-digested samples were diluted in $2 \% \mathrm{HNO}_{3}$ and their metal content analyzed on an Agilent $7700 \mathrm{x}$ ICPMS. Bismuth was used as an internal standard. Statistical analysis was performed using the Student's t-test with a $95 \%$ confidence interval.

Cell flocculation studies. Liquid cultures of PQN4 transformants with the negative control plasmid, $\mathrm{P}_{\text {merR }}$-YFP, or $\mathrm{P}_{\text {merR }}$-curli were grown for 24 hours in LB with and without $800 \mathrm{ppb}$ $\mathrm{Hg}^{2+}$. The resulting cultures, after thorough resuspension, were allowed to settle at ambient conditions and were photographed every 2 hours. The flocculation was also quantitatively measured in triplicate by monitoring the absorbance at $600 \mathrm{~nm}$ of $1 \mathrm{ml}$ cultures in cuvettes in an Agilent Cary 300 UV-Vis spectrophotometer over the course of 720 minutes. Representative microscopy images of the cultures showing cell suspensions or flocs were imaged on an EVOS FL Cell Imaging System.

\section{ASSOCIATED CONTENT Supporting Information}

The Supporting Information is available free of charge on the ACS Publications website.

Figures that provide additional data for YFP expression under the MerR promoter, the effect of mercury on the Congo Red assay, mercury sequestration by curli fibers expressed using different promoters, mercury retention by the biomass, and plasmid maps of the constructs used in this work, and listing of sequence information. 


\section{AUTHOR INFORMATION}

\section{Corresponding Author}

Dr. Neel S. Joshi

School of Engineering and Applied Sciences /

Wyss Institute for Biologically Inspired Engineering

Harvard University

Cambridge, MA 02138, USA.

Tel: (617) 432-7732

E-mail: njoshi@seas.harvard.edu

\section{Author Contributions}

P.Q.N. and N.S.J. conceived of the concept, P.R.T. and P.Q.N. performed the experiments, and all authors contributed to the manuscript.

\section{Notes}

The authors declare no competing financial interest.

\section{ACKNOWLEDGMENTS}

This work was supported by NSF Grant 1410751 (Division of Materials Research) and the Wyss Institute for Biologically Inspired Engineering. P.R. Tay acknowledges support by the Agency for Science, Technology and Research (A*STAR) in Singapore.

\section{Table of Contents Figure}

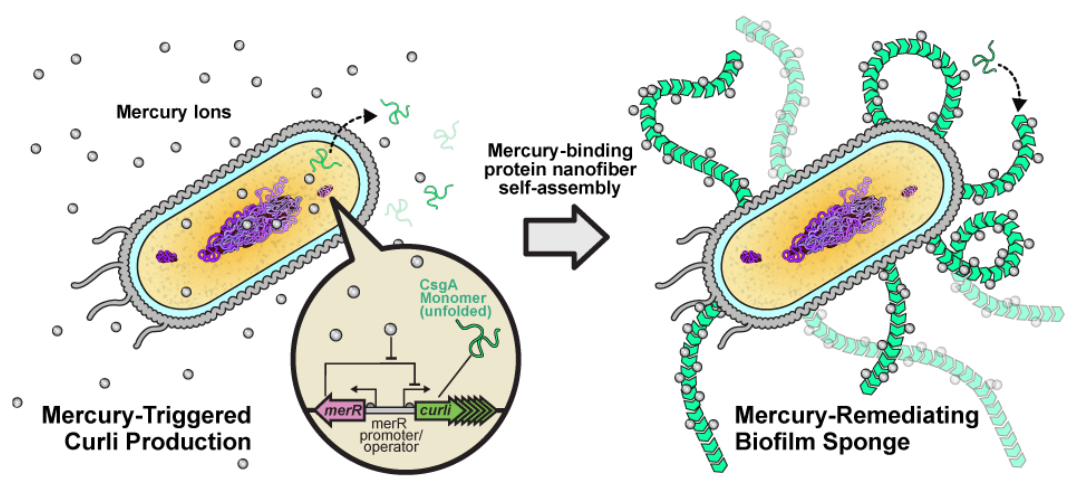




\section{References}

[1] Driscoll, C. T., Mason, R. P., Chan, H. M., Jacob, D. J., and Pirrone, N. (2013) Mercury as a global pollutant: sources, pathways, and effects, Environ Sci Technol 47, 4967-4983.

[2] Suedel, B. C., Boraczek, J. A., Peddicord, R. K., Clifford, P. A., and Dillon, T. M. (1994) Trophic transfer and biomagnification potential of contaminants in aquatic ecosystems, In Rev Environ Contam Toxicol (Ware, G. W., Ed.), pp 21-89, Springer New York, New York, NY.

[3] Guzzi, G., and La Porta, C. A. (2008) Molecular mechanisms triggered by mercury, Toxicol 244, 1-12.

[4] Jain, A., Barrile, R., van der Meer, A. D., Mammoto, A., Mammoto, T., De Ceunynck, K., Aisiku, O., Otieno, M. A., Louden, C. S., Hamilton, G. A., Flaumenhaft, R., and Ingber, D. E. (2017) A primary human lung alveolus-on-a-chip model of intravascular thrombosis for assessment of therapeutics, Clinical Pharmacology \& Therapeutics.

[5] Eagles-Smith, C. A., Wiener, J. G., Eckley, C. S., Willacker, J. J., Evers, D. C., MarvinDiPasquale, M. C., Obrist, D., Aiken, G. R., Lepak, J. M., Jackson, A. K., Webster, J., Stewart, R., Davis, J., Alpers, C. N., and Ackerman, J. (2016) Mercury in western North America: A synthesis of environmental contamination, fluxes, bioaccumulation, and risk to fish and wildlife, Sci Tot Environ 568, 1213-1226.

[6] O'Halloran, T., and Walsh, C. (1987) Metalloregulatory DNA-binding protein encoded by the merR gene: isolation and characterization, Science (New York, N.Y.) 235, 211-214.

[7] Summers, A. O. (1992) Untwist and shout: a heavy metal-responsive transcriptional regulator, J Bacteriol 174, 3097-3101.

[8] Virta, M., Lampinen, J., and Karp, M. (1995) A luminescence-based mercury biosensor, Anal Chem 67, 667-669.

[9] Hakkila, K., Maksimow, M., Karp, M., and Virta, M. (2002) Reporter genes lucFF, luxCDABE, gfp, and dsred have different characteristics in whole-cell bacterial sensors, Analytical biochemistry 301, 235-242.

[10] Chen, S., and Wilson, D. B. (1997) Construction and characterization of Escherichia coli genetically engineered for bioremediation of $\mathrm{Hg}(2+)$-contaminated environments, Appl Environ Microbiol 63, 2442-2445.

[11] Lin, K. H., Chien, M. F., Hsieh, J. L., and Huang, C. C. (2010) Mercury resistance and accumulation in Escherichia coli with cell surface expression of fish metallothionein, Appl Microbiol Biotechnol 87, 561-569.

[12] Bae, W., Wu, C. H., Kostal, J., Mulchandani, A., and Chen, W. (2003) Enhanced mercury biosorption by bacterial cells with surface-displayed MerR, Appl Environ Microbiol 69, 3176-3180.

[13] Qin, J., Song, L., Brim, H., Daly, M. J., and Summers, A. O. (2006) Hg(II) sequestration and protection by the MerR metal-binding domain (MBD), Microbiol 152, 709-719.

[14] Francois, F., Lombard, C., Guigner, J. M., Soreau, P., Brian-Jaisson, F., Martino, G., Vandervennet, M., Garcia, D., Molinier, A. L., Pignol, D., Peduzzi, J., Zirah, S., and Rebuffat, S. (2012) Isolation and characterization of environmental bacteria capable of extracellular biosorption of mercury, Appl Environ Microbiol 78, 1097-1106.

[15] Meliani, A., Bensoltane, A. (2016) Biofilm-mediated heavy metals bioremediation in PGPR Pseudomonas, $J$ Bioremed Biodegrad 7. 
[16] Ishikawa, S., and Suyama, K. (1998) Recovery and refining of au by gold-cyanide ion biosorption using animal fibrous proteins, Appl Biochem Biotechnol 70, 719-728.

[17] Malik, D. S., Jain, C. K., and Yadav, A. K. (2016) Removal of heavy metals from emerging cellulosic low-cost adsorbents: a review, Appl Water Sci.

[18] Bolisetty, S., and Mezzenga, R. (2016) Amyloid-carbon hybrid membranes for universal water purification, Nature nanotechnology 11, 365-371.

[19] Hane, F., Tran, G., Attwood, S. J., and Leonenko, Z. (2013) Cu2+ Affects Amyloid- $\beta$ (142) Aggregation by Increasing Peptide-Peptide Binding Forces, PLOS ONE 8, e59005.

[20] Rufo, C. M., Moroz, Y. S., Moroz, O. V., Stöhr, J., Smith, T. A., Hu, X., DeGrado, W. F., and Korendovych, I. V. (2014) Short peptides self-assemble to produce catalytic amyloids, Nat Chem 6, 303-309.

[21] Sarell, C. J., Syme, C. D., Rigby, S. E., and Viles, J. H. (2009) Copper(II) binding to amyloid-beta fibrils of Alzheimer's disease reveals a picomolar affinity: stoichiometry and coordination geometry are independent of Abeta oligomeric form, Biochemistry 48, 4388-4402.

[22] Eskici, G., and Axelsen, P. H. (2012) Copper and Oxidative Stress in the Pathogenesis of Alzheimer's Disease, Biochemistry 51, 6289-6311.

[23] Sternisha, A., and Makhlynets, O. (2017) Catalytic Amyloid Fibrils That Bind Copper to Activate Oxygen, Methods in molecular biology (Clifton, N.J.) 1596, 59-68.

[24] Knowles, T. P., and Mezzenga, R. (2016) Amyloid Fibrils as Building Blocks for Natural and Artificial Functional Materials, Advanced materials (Deerfield Beach, Fla.) 28, 6546-6561.

[25] Seker, U. O. S., Chen, A. Y., Citorik, R. J., and Lu, T. K. (2017) Synthetic Biogenesis of Bacterial Amyloid Nanomaterials with Tunable Inorganic-Organic Interfaces and Electrical Conductivity, ACS Synth Biol 6, 266-275.

[26] Shen, Y., Posavec, L., Bolisetty, S., Hilty, F. M., Nyström, G., Kohlbrecher, J., Hilbe, M., Rossi, A., Baumgartner, J., Zimmermann, M. B., and Mezzenga, R. (2017) Amyloid fibril systems reduce, stabilize and deliver bioavailable nanosized iron, Nature nanotechnology 12, 642-647.

[27] Chen, A. Y., Zhong, C., and Lu, T. K. (2015) Engineering Living Functional Materials, ACS Synth Biol 4, 8-11.

[28] Nguyen, P. Q. (2017) Synthetic biology engineering of biofilms as nanomaterials factories, Biochemical Society transactions 45, 585-597.

[29] Chapman, M. R., Robinson, L. S., Pinkner, J. S., Roth, R., Heuser, J., Hammar, M., Normark, S., and Hultgren, S. J. (2002) Role of Escherichia coli curli operons in directing amyloid fiber formation, Science (New York, N.Y.) 295, 851-855.

[30] Botyanszki, Z., Tay, P. K. R., Nguyen, P. Q., Nussbaumer, M. G., and Joshi, N. S. (2015) Engineered catalytic biofilms: Site-specific enzyme immobilization onto E. coli curli nanofibers, Biotechnol Bioeng 112, 2016-2024.

[31] Chen, A. Y., Deng, Z., Billings, A. N., Seker, U. O., Lu, M. Y., Citorik, R. J., Zakeri, B., and Lu, T. K. (2014) Synthesis and patterning of tunable multiscale materials with engineered cells, Nature materials 13, 515-523.

[32] Nguyen, P. Q., Botyanszki, Z., Tay, P. K., and Joshi, N. S. (2014) Programmable biofilmbased materials from engineered curli nanofibres, Nature communications 5, 4945. 
[33] Zhong, C., Gurry, T., Cheng, A. A., Downey, J., Deng, Z., Stultz, C. M., and Lu, T. K. (2014) Strong underwater adhesives made by self-assembling multi-protein nanofibres, Nature nanotechnology 9, 858-866.

[34] Pawar, D. M., Rossman, M. L., and Chen, J. (2005) Role of curli fimbriae in mediating the cells of enterohaemorrhagic Escherichia coli to attach to abiotic surfaces, Journal of applied microbiology 99, 418-425.

[35] Kikuchi, T., Mizunoe, Y., Takade, A., Naito, S., and Yoshida, S. (2005) Curli fibers are required for development of biofilm architecture in Escherichia coli K-12 and enhance bacterial adherence to human uroepithelial cells, Microbiology and immunology 49, 875884.

[36] Uhlich, G. A., Gunther, N. W., Bayles, D. O., and Mosier, D. A. (2009) The CsgA and Lpp proteins of an Escherichia coli O157:H7 strain affect HEp-2 cell invasion, motility, and biofilm formation, Infect Imm 77, 1543-1552.

[37] Hidalgo, G., Chen, X., Hay, A. G., and Lion, L. W. (2010) Curli produced by Escherichia coli PHL628 provide protection from Hg(II), Appl Environ Microbiol 76, 6939-6941.

[38] Dorval Courchesne, N.-M., Duraj-Thatte, A., Tay, P. K. R., Nguyen, P. Q., and Joshi, N. S. (2016) Scalable production of genetically engineered nanofibrous macroscopic materials via filtration, ACS Biomater Sci Eng.

[39] Andersson, E. K., Bengtsson, C., Evans, M. L., Chorell, E., Sellstedt, M., Lindgren, A. E., Hufnagel, D. A., Bhattacharya, M., Tessier, P. M., Wittung-Stafshede, P., Almqvist, F., and Chapman, M. R. (2013) Modulation of curli assembly and pellicle biofilm formation by chemical and protein chaperones, Chemistry \& biology 20, 1245-1254.

[40] Barnhart, M. M., and Chapman, M. R. (2006) Curli biogenesis and function, Annual review of microbiology 60, 131-147.

[41] Wang, X., Hammer, N. D., and Chapman, M. R. (2008) The molecular basis of functional bacterial amyloid polymerization and nucleation, The Journal of biological chemistry 283, 21530-21539.

[42] Arnqvist, A., Olsen, A., Pfeifer, J., Russell, D. G., and Normark, S. (1992) The Crl protein activates cryptic genes for curli formation and fibronectin binding in Escherichia coli HB101, Molecular microbiology 6, 2443-2452.

[43] Jubelin, G., Vianney, A., Beloin, C., Ghigo, J. M., Lazzaroni, J. C., Lejeune, P., and Dorel, C. (2005) CpxR/OmpR interplay regulates curli gene expression in response to osmolarity in Escherichia coli, J Bacteriol 187, 2038-2049.

[44] Nies, D. H. (1999) Microbial heavy-metal resistance, Appl Microbiol Biotechnol 51, 730750.

[45] Bell, L. (2016) Guidance on the identification, management and remediation of mercurycontaminated sites, (IPEN, Ed.).

[46] Huang, X. D., Atwood, C. S., Hartshorn, M. A., Multhaup, G., Goldstein, L. E., Scarpa, R. C., Cuajungco, M. P., Gray, D. N., Lim, J., Moir, R. D., Tanzi, R. E., and Bush, A. I. (1999) The A-beta peptide of Alzheimer's disease directly produces hydrogen peroxide through metal ion reduction, Biochem 38, 7609-7616.

[47] Hseu, Z. Y., Huang, Y. T., and Hsi, H. C. (2014) Effects of remediation train sequence on decontamination of heavy metal-contaminated soil containing mercury, Journal of the Air \& Waste Management Association (1995) 64, 1013-1020. 
[48] Ralston, D. M., and Ohalloran, T. V. (1990) Ultrasensitivity and heavy-metal selectivity of the allosterically modulated merR transcription complex, Proc Nat Acad Sci USA 87, 3846-3850.

[49] Chu, L., Mukhopadhyay, D., Yu, H. G., Kim, K. S., and Misra, T. K. (1992) Regulation of the Staphylococcus aureus plasmid-pi258 mercury resistance operon, J Bacteriol 174, 7044-7047.

[50] House, E., Collingwood, J., Khan, A., Korchazkina, O., Berthon, G., and Exley, C. (2004) Aluminium, iron, zinc and copper influence the in vitro formation of amyloid fibrils of Abeta42 in a manner which may have consequences for metal chelation therapy in Alzheimer's disease, Journal of Alzheimer's disease : JAD 6, 291-301.

[51] Liu, D., Xiao, Y., Evans, B. S., and Zhang, F. (2015) Negative Feedback Regulation of Fatty Acid Production Based on a Malonyl-CoA Sensor-Actuator, ACS Synth Biol

4, 132-140.

[52] Oyarzún, D. A., Lugagne, J.-B., and Stan, G.-B. V. (2015) Noise Propagation in Synthetic Gene Circuits for Metabolic Control, ACS Synth Biol 4, 116-125.

[53] Stapleton, J. A., Endo, K., Fujita, Y., Hayashi, K., Takinoue, M., Saito, H., and Inoue, T. (2012) Feedback Control of Protein Expression in Mammalian Cells by Tunable Synthetic Translational Inhibition, ACS Synth Biol 1, 83-88.

[54] Bansal, K., Yang, K., Nistala, G. J., Gennis, R. B., and Bhalerao, K. D. (2010) A positive feedback-based gene circuit to increase the production of a membrane protein, Journal of biological engineering 4, 6 .

[55] Harrison, M. E., and Dunlop, M. J. (2012) Synthetic feedback loop model for increasing microbial biofuel production using a biosensor, Front Microbiol 3, 360.

[56] Tipping, E., Lofts, S., Hooper, H., Frey, B., Spurgeon, D., and Svendsen, C. (2010) Critical Limits for $\mathrm{Hg}(\mathrm{II})$ in soils, derived from chronic toxicity data, Environmental pollution (Barking, Essex : 1987) 158, 2465-2471.

[57] Bueno, P. C., Bellido, E., Rubí, J. A. M., and Ballesta, R. J. (2009) Concentration and spatial variability of mercury and other heavy metals in surface soil samples of periurban waste mine tailing along a transect in the Almadén mining district (Spain), Environmental Geology 56, 815-824.

[58] Fashola, M. O., Ngole-Jeme, V. M., and Babalola, O. O. (2016) Heavy Metal Pollution from Gold Mines: Environmental Effects and Bacterial Strategies for Resistance, International journal of environmental research and public health 13.

[59] Collinson, S. K., Parker, J. M. R., Hodges, R. S., and Kay, W. W. (1999) Structural predictions of AgfA, the insoluble fimbrial subunit of Salmonella thin aggregative fimbriae1, J Mol Biol 290, 741-756.

[60] Hammar, M., Bian, Z., and Normark, S. (1996) Nucleator-dependent intercellular assembly of adhesive curli organelles in Escherichia coli, Proc Natl Acad Sci USA 93, 6562-6566.

[61] Evans, M. L., and Chapman, M. R. (2014) Curli biogenesis: order out of disorder, Biochimica et biophysica acta 1843, 1551-1558.

[62] Sleutel, M., Van den Broeck, I., Van Gerven, N., Feuillie, C., Jonckheere, W., Valotteau, C., Dufrene, Y. F., and Remaut, H. (2017) Nucleation and growth of a bacterial functional amyloid at single-fiber resolution, Nat Chem Biol advance online publication.

[63] Dueholm, M. S., Albertsen, M., Otzen, D., and Nielsen, P. H. (2012) Curli functional amyloid systems are phylogenetically widespread and display large diversity in operon and protein structure, PLoS One 7, e51274. 
[64] Hakkila, K. M., Nikander, P. A., Junttila, S. M., Lamminmaki, U. J., and Virta, M. P. (2011) Cd-specific mutants of mercury-sensing regulatory protein MerR, generated by directed evolution, Appl Environ Microbiol 77, 6215-6224.

[65] Li, L., Liang, J., Hong, W., Zhao, Y., Sun, S., Yang, X., Xu, A., Hang, H., Wu, L., and Chen, S. (2015) Evolved bacterial biosensor for arsenite detection in environmental water, Environ Sci Technol 49, 6149-6155.

[66] Anbu, P., Kang, C.-H., Shin, Y.-J., and So, J.-S. (2016) Formations of calcium carbonate minerals by bacteria and its multiple applications, SpringerPlus 5, 250.

[67] Harris, D., Ummadi, J. G., Thurber, A. R., Allau, Y., Verba, C., Colwell, F., Torres, M. E., and Koley, D. (2016) Real-time monitoring of calcification process by Sporosarcina pasteurii biofilm, Analyst 141, 2887-2895.

[68] Hazen, T. C., and Tabak, H. H. (2005) Developments in Bioremediation of Soils and Sediments Polluted with Metals and Radionuclides: 2. Field Research on Bioremediation of Metals and Radionuclides, Rev Environ Sci Bio/Technol 4, 157-183.

[69] (2007) Treatment Technologies for Mercury in Soil, Waste, and Water, (Agency, U. S. E. P., Ed.).

[70] Abouseoud, M., Yataghene, A., Amrane, A., and Maachi, R. (2008) Biosurfactant production by free and alginate entrapped cells of Pseudomonas fluorescens, J Indust Microbiol Biotechnol 35, 1303-1308.

[71] Menendez-Vega, D., Gallego, J. L. R., Pelaez, A. I., Fernandez de Cordoba, G., Moreno, J., Muñoz, D., and Sanchez, J. (2007) Engineered in situ bioremediation of soil and groundwater polluted with weathered hydrocarbons, Eur J Soil Biol 43, 310-321.

[72] Mrozik, A., and Piotrowska-Seget, Z. (2010) Bioaugmentation as a strategy for cleaning up of soils contaminated with aromatic compounds, Microbiological research 165, 363-375.

[73] Riis, C. E., Christensen, A. G., Mortensen, A. P., and Jannerup, H. (2010) Bioremediation of TCE in a fractured limestone aquifer using a novel horizontal passive biobarrier, Remed J 20, 27-43.

[74] Ross, N., and Bickerton, G. (2002) Application of Biobarriers for Groundwater Containment at Fractured Bedrock Sites, Remed J 12, 5-21.

[75] (2010) FRTR Cost and Performance Case Studies, (Roundtable, F. R. T., Ed.).

[76] Singh, J. S., Abhilash, P. C., Singh, H. B., Singh, R. P., and Singh, D. P. (2011) Genetically engineered bacteria: an emerging tool for environmental remediation and future research perspectives, Gene 480, 1-9.

[77] Sayler, G. S., and Ripp, S. (2000) Field applications of genetically engineered microorganisms for bioremediation processes, Current opinion in biotechnology 11, 286289.

[78] Valls, M., and de Lorenzo, V. (2002) Exploiting the genetic and biochemical capacities of bacteria for the remediation of heavy metal pollution, FEMS microbiology reviews 26, 327-338.

[79] Fernandez-López, R., Ruiz, R., de la Cruz, F., and Moncalián, G. (2015) Transcription factor-based biosensors enlightened by the analyte, Front Microbiol 6, 648.

[80] Nielsen, P. H., Dueholm, M. S., Thomsen, T. R., Nielsen, J. L., and Otzen, D. (2011) Functional bacterial amyloids in biofilms, In Biofilm Highlights (Flemming, H.-C., Wingender, J., and Szewzyk, U., Eds.), pp 41-62, Springer Berlin Heidelberg, Berlin, Heidelberg. 